\title{
Optimum PID controller for airplane wing tires based on gravitational search algorithm
}

\author{
Ammar Hussein Mutlag, Omar Nameer Mohammed Salim, Siraj Qays Mahdi \\ Department of Computer Engineering Techniques, Middle Technical University, Baghdad, Iraq
}

\begin{tabular}{l} 
Article Info \\
\hline Article history: \\
Received Mar 7, 2021 \\
Revised May 20, 2021 \\
Accepted Jun 13, 2021 \\
\hline
\end{tabular}

Keywords:

Airplane wing tires

Meta-heuristic optimization

PID controller

Transfer functions

Ziegler Nichols

\begin{abstract}
In this paper, the gravitational search algorithm (GSA) is proposed as a method for controlling the opening and closing of airplane wing tires. The GSA is used to find the optimum proportional-integral-derivative (PID) controller, which controls the wing tires during take-off and landing. In addition, the GSA is suggested as an approach for overcoming the absence of the transfer function, which is usually required to design the optimum PID. The use of the GSA is expected to improve the system. Two of the most popular optimisation algorithms-the harmony search algorithm (HSA) and the particle swarm optimisation (PSO)-were used for the sake of comparison. Moreover, the GSA-, HSA- and PSO-based optimum PID controllers were compared with one of the most important PID tuning methods, the ZieglerNichols (ZN) method. In this study, the integral time absolute error (ITAE) was used as a fitness function. First, four transfer functions for different applications were used to compare the performance of the GSA-based PID (PID-GSA), HSA-based PID (PID-HSA), PSO-based PID (PID-PSO) and Ziegler-Nichols-based PID (PID-ZN). Next, the GSA was used to design the optimum PID controller for the opening and closing systems of the airplane wing tires. The results reveal that the GSA provides better outcomes in terms of ITAE when compared with the other adopted algorithms. Furthermore, the GSA demonstrates a fast and robust response to reference variation.
\end{abstract}

This is an open access article under the $\underline{C C B Y-S A}$ license.

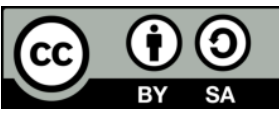

\section{Corresponding Author:}

Siraj Qays Mahdi

Department of Computer Engineering Techniques

Middle Technical University

Baghdad, Iraq

Email: siraj_qays@mtu.edu.iq

\section{INTRODUCTION}

Controlling the wing tires is an important aspect of airplane take-off and landing. There are many challenges associated with the control process, such as settling time, rise time, overshoot and steady-state error [1]. The goal is always to enhance the transient and steady-state performance of a system [2]. Accordingly, the design of a robust controller for the purpose of opening and closing the wing tires is an important matter [3]. One of the most important controllers reported in the literature is the PID controller [4]. The performance of the PID controller depends on three parameters: proportional gain $\left(\mathrm{K} \_\mathrm{p}\right)$, integral gain $\left(\mathrm{K} \_\mathrm{i}\right)$ and derivative gain (K_d) [5]. These parameters produce an expected transient response which corresponds to each operating point [6]. A first and integral step in designing the PID controller is deriving an appropriate mathematical model; after this, various techniques can be implemented to determine PID parameters (K_p, $K_{-} i$ and $\left.K \_d\right)$. In the literature, the $Z N$ technique is the one of the most important for designing the PID controller [7]. 
However, the derivation process for the mathematical model is complicated-sometimes impossible. Recently, however, complex, real-world problems have been solved using computational intelligence optimisation algorithms (CIOAs) [8]. The term 'computational intelligence' indicates solving a problem using artificial or natural populations, and suggests that complex problems can be solved using CIOAs. Thus, CIOAs are suggested in this paper in the absence of a mathematical model. Furthermore, the use of CIOAs is expected to improve the opening and closing system of the wing tires. A CIOA can often solve a problem more quickly, or find an approximate solution when classical methods fail, especially in the case of multimodal optimisation problems [9]. Many CIOAs are mentioned in the literature. These algorithms can be divided in two groups: evolutionary and swarm intelligence algorithms [10].

Darwin's theory of evolution is fundamental to the evolutionary algorithmic group, the most popular paradigms of which are the genetic algorithm (GA) [11], evolutionary programming [12], differential evolution [13], evolutionary strategy [14] and genetic programming [15]. However, falling into local minima and difficulty finding the optimum solution to the multimodal problem are the main drawbacks of these algorithms.

The second group is swarm intelligence, the algorithms of which mimic the social behaviour of animals and insects [16]. PSO [17], ant colony optimisation (ACO) [18] and artificial bee colony optimisation (ABC) [19] are the main paradigms. The PSO algorithm is one of the modern heuristic algorithms, it was enlivened by the social behavior of bird and fish tutoring and has been discovered to be vigorous in solving continuous nonlinear optimization problems [20]. Where, PSO algorithm is applied to improve the surface grinding process parameter in both rough and finish grinding condition. The The ideal worth of the decision factors were acquired by utilizing the mathematical model with the purpose of decreasing the production cost and expanding the production rate as well as improving the surface finish [21].

The main limiting factors of these algorithms are early convergence and stagnation in local minima. Other swam intelligence optimisation algorithms have been developed such as such as HSA [22], GSA [23], firefly algorithm (FFA) [24] and bat algorithm (BA) [25]. This study aims to present a method for finding the optimum PID controller in the cases of both absence and presence the transfer function of any system. For this purpose, a well-known meta-heuristic optimisation called GSA is used. This method aims to improve the performance of any system. Furthermore, it is intended to solve the problem of trial and error in determining the parameters of the PID controller, which are K_p, K_i and K_d. Therefore, the use of the GSA is expected to enhance the system response. For this purpose, a formulated fitness function, ITAE, is used. The GSA aims to reduce ITAE by regulating the control parameters (K_p, K_i andK_d) of PID controller during the design phase.

\section{PROPOSED CONTROLLER OVER WINGS TIRES}

The most important element of the control process of the wing tires is the proper selection of the PID parameters. The improper selection of these parameters will lead to a bad response in the process of opening and closing the wing tires. Accordingly, this paper presents a methodology for designing the PID controller without a mathematical model, instead using meta-heuristic optimisation algorithms. This process will avoid the trial and error process in the design of the controller. Moreover, this methodology is expected to enhance the performance of the opening and closing process of the wing tires.

\subsection{Proposed meta-heuristic optimisation algorithms}

In recent years, meta-heuristic optimisation algorithms have been used to solve problems in various fields, such as commerce, economics and engineering. Meta-heuristic optimisation algorithms are often used based on their ability to address complex problems in real-world situations; ease of use and efficiency also contribute to their attractiveness. In this work, a GSA has been developed to enhance the opening and closing process in wing tires. Through the use of this algorithm, an improvement in the performance of the airplane wing tires is expected.

\subsection{Formulation of the optimal PID controller}

The formulation process for the optimisation-based wing tires consisted of three parts: the determination of the search space size; the formulation of a suitable fitness function for the system; and the identification of optimisation limitations. The optimisation algorithm search the optimum value of the search space through depending on the fitness function and optimisation controls.

\subsubsection{Size of the search space}

The size of the search space means the input variables through which the optimisation algorithm should find their optimal solutions. The size of the search space can be expressed as: 


$$
I_{i, j}=\left[K_{1}^{i, j}, \ldots . K_{n}^{i, j}\right]
$$

The $I_{i, j}$ is the jth solution in the agents through the ith iteration, $K_{t}^{i, j}$ is the tth element of $I_{i, j}$, and $\mathrm{n}$ is the total number of variables.

\subsubsection{Fitness function}

The second component of the optimisation process is the fitness function, which is important for evaluating the performance of the optimisation algorithm. Accordingly, the fitness function has been developed to find the optimum design of the PID controller in such a way that the $I_{i, j}$ generates the optimum control action. ITAE has been developed as the fitness function, and is found by taking the difference between the reference input $\left(Y_{\text {in }}\right)$ and the measured output $\left(Y_{\text {out }}\right)$. The ITAE is expressed by:

$$
\operatorname{ITAE}=\int_{0}^{s} t\left|Y_{\text {in }}(t)-Y_{\text {out }}(t)\right| d t
$$

Where $Y_{\text {in }}$ is the reference input, $Y_{\text {out }}$ is the measured output and $\mathrm{s}$ is the sample number.

During the optimisation process, a minimal fitness function indicates an effective system; thus, the optimisation algorithm is aiming to minimize ITAE.

\section{PROPOSED CONTROLLER-BASED WING TIRES}

To demonstrate the effect of the proposed controller on the opening and closing of the airplane wing tires, the system has been modelled using MATLAB environment, as shown in Figure 1. The output signal $\left(Y_{\text {out }}\right)$ is measured and compared with the input signal $\left(Y_{i n}\right)$. The difference signal between $Y_{i n}$ and $Y_{\text {out }}$ is fed into the optimisation algorithm to find the optimum $K_{p}, K_{i}$ and $K_{d}$ of the PID controller. As mentioned before, the GSA has been used to enhance the opening and closing of the wing tires. The performance of the GSA has been compared with HAS and PSO. Each algorithm has special variables that differ from those of other algorithms. These parameters must be settled in the initialisation stage. The algorithm parameters are listed in Table 1.

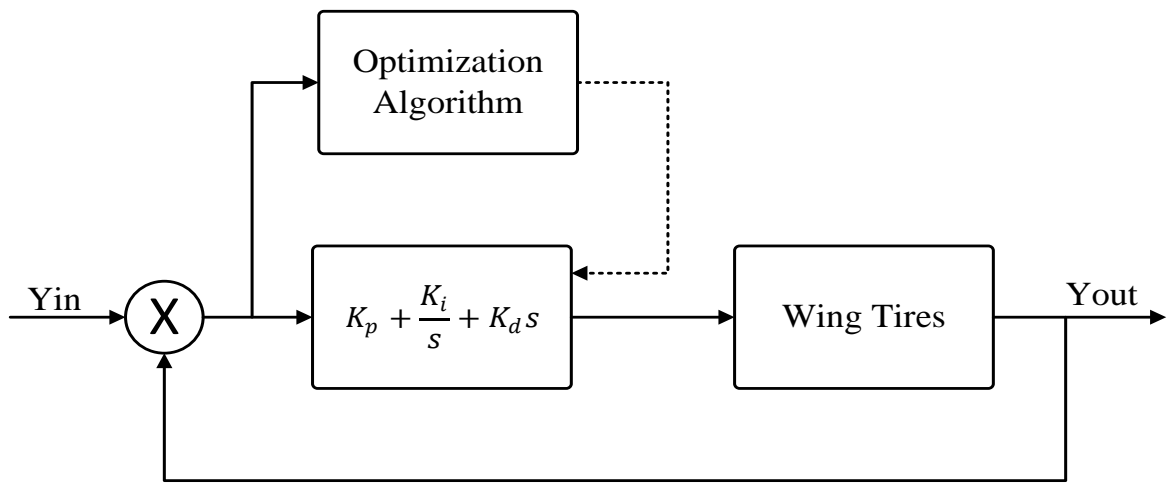

Figure 1. Closed-loop system of the wing tires

Table 1. Parameters of the optimisation algorithms

\begin{tabular}{lccc}
\hline \multicolumn{1}{c}{ Parameter } & GSA & HAS & PSO \\
\hline Agent Size (N) & 20 & 20 & 20 \\
Maximum Iteration (T) & 500 & 500 & 500 \\
Initial gravity & 100 & - & - \\
E & $2.2204 \mathrm{e}-16$ & - & - \\
Harmony consideration rate & - & 0.9 & - \\
Minimum pitch adjusting rate & - & 0.4 & - \\
Maximum pitch adjusting rate & - & 0.9 & - \\
Minimum bandwidth & - & 0.0001 & - \\
Maximum bandwidth & - & 1 & - \\
$\alpha_{i}, \beta_{f}$ & - & - & 2.5 \\
$\beta_{i}, \alpha_{f}$ & - & - & 0.5 \\
\hline
\end{tabular}

\section{IMPLEMENTATION OF THE GSA}

As mentioned before, the GSA has been used to improve the opening and closing system of an airplane's wing tires. Introduced by Rashedi et al. [23], the GSA is a meta-heuristic optimisation algorithm 
inspired by the law of gravity. Accordingly, this algorithm is based on Newtonian gravity. The implementation of the GSA in the design process for the PID controller-based wing tires begins by resetting the GSA parameters. These parameters are number of agent $(\mathrm{N})$, number of iteration $(\mathrm{T})$, initial gravity and final Kbest. The initial agents are encoded using (1). The evaluations of these agents are achieved using (3). Each agent is updated through the (3):

$$
X_{i, \text { new }}^{d}=X_{i}^{d}+V_{i, \text { new }}^{d}
$$

Where velocity $\left(V_{i, \text { new }}^{d}\right)$ of each agent is calculated as:

$$
V_{i, \text { new }}^{d}=\operatorname{rand}_{i} \times V_{i}^{d}+a_{i}^{d}
$$

The acceleration of the ith agent and dth direction $\left(a_{i}^{d}\right)$ is computed as:

$$
a_{i}^{d}=\frac{F_{i}^{d}}{M_{i i}}
$$

Where $M_{i i}$ represents the inertia of the ith agent. The stochastic characteristic of the GSA algorithm has been achieved using the total force. The total force of the ith agent and dth direction $\left(F_{i}^{d}\right)$ is represented as:

$$
F_{i}^{d}=\sum_{J=1, j \neq i}^{N} \operatorname{rand} F_{i j}^{d}
$$

The force acting of the ith mass from jth mass $\left(F_{i j}^{d}\right)$ is defined as:

$$
F_{i j}^{d}=G \frac{M_{p i} \times M_{a j}}{R_{i j}+\varepsilon}\left(X_{j}^{d}-X_{i}^{d}\right)
$$

Where $G, M_{p i}, M_{a j}$, and $\varepsilon$ are the gravitational constant, passive gravitational mass of the ith agent and active gravitational mass of the jth agent, respectively. The euclidian distance between ith agent and jth agent $\left(R_{i j}\right)$ is defined as:

$$
R_{i j}=\left\|X_{i}^{d}, X_{j}^{d}\right\|_{2}
$$

This process is repeated until the maximum iteration is reached, as shown in Figure 2 in appendix.

\section{RESULTS AND DISCUSSION}

Two tests have been carried out in this study. Presented in section 5.1, the first test shows the performance of the GSA in designing the PID controller for some plants. The second test, presented in section 5.2, shows the performance of the GSA in solving the problem of trial and error procedure when designing the PID controller for opening and closing systems for airplane wing tires.

\subsection{Test-1}

The GSA has been used to design an optimum PID controller. The GSA has also been compared with HSA and PSO. For further comparison, the ZN method, a renowned PID tuning method, has also been used in the design of optimum PID controllers. Four different transfer functions, shown in Table 2, have been used to evaluate the four controllers (PID-GSA, PID-HSA, PID-PSO, and PID-ZN). The results of these controllers, based on ITAE, are shown in Table 3, and the best performance is bolded. Table 3 clearly indicates that the GSA, HAS and PSO have achieved minimum ITAE when compared to ZN. Furthermore, Table 3 shows that the performance of the PID-GSA is better than the other controller for all transfer functions. This highlights the robustness of the PID-GSA.

The convergence characteristics of the GSA-, HAS- and PSO-based first-transfer function $\left(G_{1}\right)$ are shown in Figure 3. Compared to the other algorithms, the GSA achieved fast convergence. Thus, the GSA has superior convergence characteristics for this transfer function. Furthermore, the GSA achieves minimum ITAE compared to the HSA and PSO. The step response of the $G_{1}$ is shown in Figure 4, and shows that the PID-GSA first-transfer function performs better than the other controllers. The PID-GSA achieves faster rise time, minimum overshoot and minimum peak time, indicating high efficiency.

The comparison between PID-GSA, PID-HSA, PID-PSO and PID-ZN for four transfer functions is presented in Table 4. In a control system, rise time, settling time, overshoot and peak time are the main parameters considered; these are shown in Table 4. The best performances are bolded. For all tested transfer functions, the GSA achieved the best results. This underscores the validity of the GSA and its ability to deal with different types of transfer function. 
Table 2. Tested transfer functions

\begin{tabular}{clll}
\hline ID & Plant & \multicolumn{1}{c}{ Name } & \multicolumn{1}{c}{ Transfer function of the plant } \\
\hline 1 & $G_{1}(s)$ & Heat exchanger Temperature & $G_{1}(s)=\frac{0.2304 s+0.01265}{s^{2}+0.06689 s+0.005244}$ \\
2 & $G_{2}(s)$ & Satellite model & $G_{2}(s)=\frac{1.269}{(s+2.723)(s+2.432)}$ \\
3 & $G_{3}(s)$ & Water tube & $G_{3}(s)=\frac{(1.25)(0.92)}{(3 s+1)(29 s+1)}$ \\
4 & $G_{4}(s)$ & Potential hydrogen neutralization & $G_{4}(s)=\frac{5.54}{2.210 s+1}$ \\
\hline
\end{tabular}

Table 3. Results of all optimisation algorithms for all plants

\begin{tabular}{ccccccc}
\hline ID & Plant & Method & \multicolumn{1}{c}{$K_{p}$} & $K_{i}$ & $K_{d}$ & ITAE \\
\hline 1 & Heat exchanger & PID-GSA & 22.3663 & 9.0319 & 1.0912 & 1.6990 \\
& & PID-HSA & 13.6852 & 9.9338 & 1.0180 & 1.8923 \\
& & PID-PSO & 12.0639 & 9.8883 & 1.0203 & 1.9740 \\
& & PID-ZN & 2.8272 & 1 & 0.25 & 13.8320 \\
2 & \multirow{4}{*}{ Satellite model } & PID-GSA & 32.8582 & 22.9864 & 3.6112 & 0.4774 \\
& & PID-HSA & 21.8426 & 19.6855 & 2.3160 & 0.6243 \\
& & PID-PSO & 17.8358 & 18.6048 & 1.5826 & 0.7028 \\
& & PID-ZN & 30 & 20 & 5 & 0.9989 \\
3 & Water tube & PID-GSA & 157.5407 & 41.2388 & 3.9137 & 5.8112 \\
& & PID-HSA & 105.2762 & 1.6099 & 28.9902 & 6.2834 \\
& & PID-PSO & 100.3626 & 31.32554 & 11.25852 & 7.0740 \\
4 & Potential & PID-ZN & 78 & 1.5 & 0.375 & 23.2565 \\
& hydrogen & PID-GSA & 19.6946 & 1.21654 & 2.65325 & 0.5864 \\
& neutralization & PID-HSA & 9.3999 & 0.8712 & 1.6747 & 0.8425 \\
& & PID-PSO & 19.4398 & 1.1738 & 2.1015 & 0.9495 \\
& & PID-ZN & 1.05880 & 1.3240 & 0.2120 & 3.9760 \\
\hline
\end{tabular}

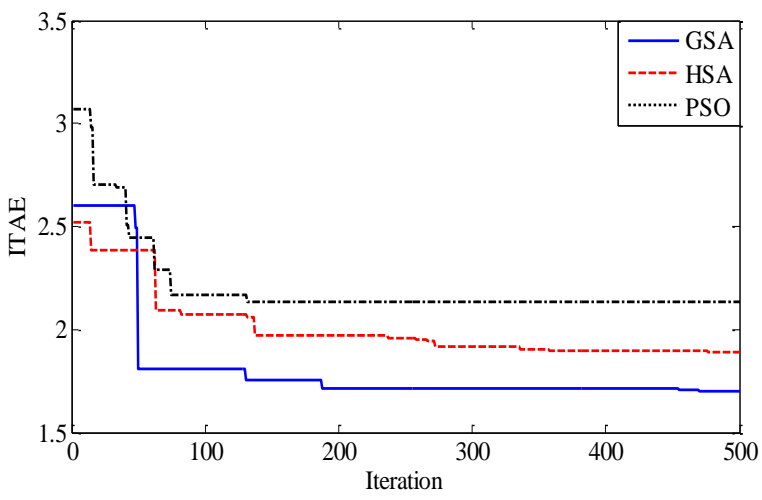

Figure 3. Convergence characteristics of the heat exchanger transfer function $\left(G_{1}\right)$

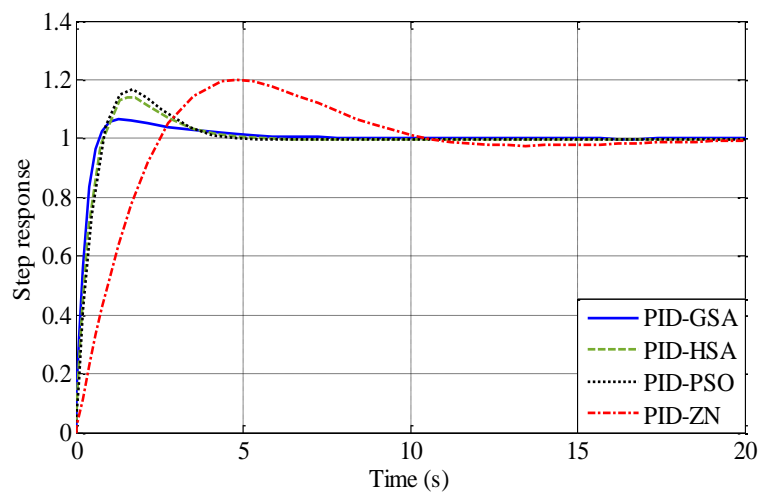

Figure 4. Step response for the heat exchanger transfer function $\left(\boldsymbol{G}_{\mathbf{1}}\right)$

Table 4. Comparison between responses of the plants based on different methods

\begin{tabular}{ccccccc}
\hline ID & Plant & Method & Rise time & Settling time & Over shoot & Peak time \\
\hline 1 & Heat exchanger & PID-GSA & $0.49 \mathrm{~s}$ & $4.2 \mathrm{~s}$ & $6.6 \%$ & $1.06 \mathrm{~s}$ \\
& & PID-HSA & $0.64 \mathrm{~s}$ & $3.9 \mathrm{~s}$ & $14.1 \%$ & $1.53 \mathrm{~s}$ \\
& & PID-PSO & $0.69 \mathrm{~s}$ & $3.8 \mathrm{~s}$ & $16.5 \%$ & $1.69 \mathrm{~s}$ \\
& & PID-ZN & $2.07 \mathrm{~s}$ & $20 \mathrm{~s}$ & $20 \%$ & $4.81 \mathrm{~s}$ \\
2 & \multirow{4}{*}{ Satellite model } & PID-GSA & $0.41 \mathrm{~s}$ & $0.9 \mathrm{~s}$ & $2.1 \%$ & $0.68 \mathrm{~s}$ \\
& & PID-HSA & $0.49 \mathrm{~s}$ & $1.3 \mathrm{~s}$ & $3.3 \%$ & $0.84 \mathrm{~s}$ \\
& & PID-PSO & $0.53 \mathrm{~s}$ & $1.4 \mathrm{~s}$ & $4.9 \%$ & $0.92 \mathrm{~s}$ \\
3 & Water tube & PID-ZN & $0.56 \mathrm{~s}$ & $3.5 \mathrm{~s}$ & $1.4 \%$ & $1.5 \mathrm{~s}$ \\
& & PID-GSA & $1.24 \mathrm{~s}$ & $13.24 \mathrm{~s}$ & $36.8 \%$ & $2.26 \mathrm{~s}$ \\
& & PID-HSA & $1.53 \mathrm{~s}$ & $18.72 \mathrm{~s}$ & $35.5 \%$ & $2.74 \mathrm{~s}$ \\
& & PID-PSO & $1.53 \mathrm{~s}$ & $22.73 \mathrm{~s}$ & $43.9 \%$ & $2.87 \mathrm{~s}$ \\
& & PID-ZN & $1.61 \mathrm{~s}$ & $26.63 \mathrm{~s}$ & $56.8 \%$ & $3.12 \mathrm{~s}$ \\
& Potential Hydrogen & PID-GSA & $0.3 \mathrm{~s}$ & $1.4 \mathrm{~s}$ & $16 \%$ & $0.5 \mathrm{~s}$ \\
& neutralization & PID-HSA & $0.42 \mathrm{~s}$ & $1.9 \mathrm{~s}$ & $18.7 \%$ & $0.72 \mathrm{~s}$ \\
& & PID-PSO & $0.31 \mathrm{~s}$ & $1.7 \mathrm{~s}$ & $24.5 \%$ & $0.5 \mathrm{~s}$ \\
& & PID-ZN & 0.75 & $3.7 \mathrm{~s}$ & $16.1 \%$ & $1.6 \mathrm{~s}$ \\
\hline
\end{tabular}

Optimum PID controller for airplane wing tires based on gravitational search ... (Ammar Hussein Mutlag) 


\subsection{Test-2}

In the second test, the GSA is used to control the process of opening and closing the airplane wing tires. The convergence characteristics of the GSA-, HAS- and PSO-based wing tire problems are exhibited in Figure 5. The figure shows that the GSA provides better solution than the other algorithms.

The performance of the GSA was compared with HAS and PSO, as well as optimum PID through MATLAB. Four controllers, PID-GSA, PID-HSA, PID-PSO and PID, are illustrated to deal with opening and closing of the wing tires of the airplane. The first test is to change the wing tire position from close to open to prepare for the landing as shown in Figure 6. The performance of the four (PID-GSA, PID-has, PIDPSO and PID) controller-based landing situations are shown in Figure 7, which clearly indicates the best performance was achieved by PID-GSA. The PID-GSA succeeds in achieving faster steady-state error, rise time and settling time than the other controllers.

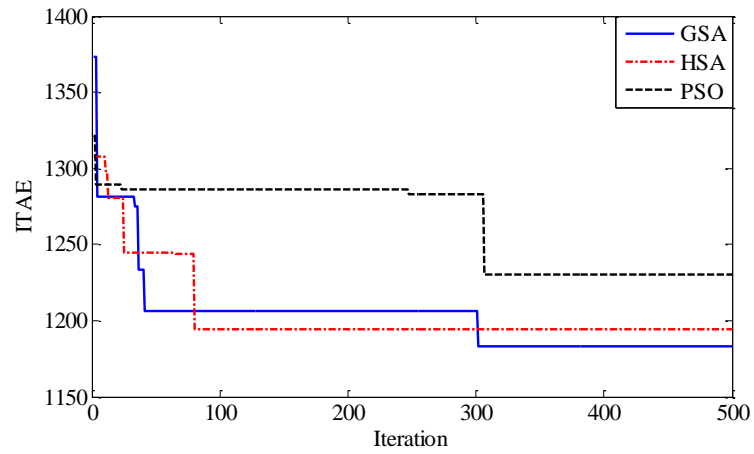

Figure 5. Convergence characteristics of GSA-HAS-and PSO-based wing tire problems

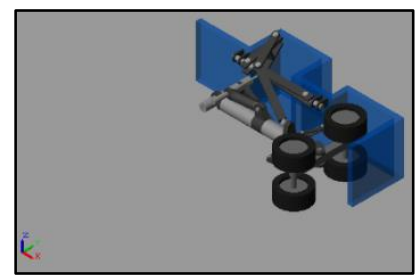

(a)

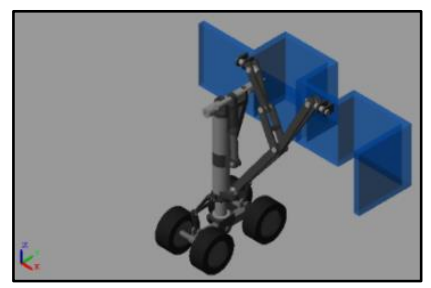

(b)

Figure 6. Change in wing tire position from, (a) close to (b) open

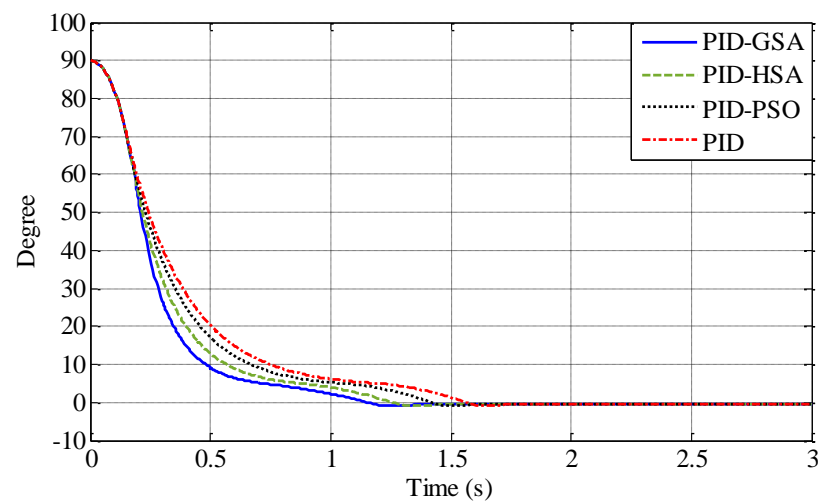

Figure 7. Response of wing tires in landing situation (from $90^{\circ}$ to $0^{\circ}$ )

The performance comparison of the PID-GSA, PID-HSA, PID-PSO and PID controller-based wing tire problems is shown in Table 5. Again, ITAE is used as the fitness function to evaluate all the controllers. The best performance is bolded. Table 5 shows that the GSA succeeds in providing better PID controller where minimum ITAE has been achieved.

Table 5. Results of four controller-based wing tire problems

\begin{tabular}{ccccc}
\hline Method & $K_{p}$ & $K_{i}$ & $K_{d}$ & ITAE \\
\hline PID-GSA & $2.999345097233 \mathrm{e}+05$ & 1.159227855138 & $4.097434603125 \mathrm{e}+04$ & $1.1830 \mathrm{e}+03$ \\
PID-HSA & $2.610763651923 \mathrm{e}+05$ & 1.863932871596 & $5.653000411136 \mathrm{e}+04$ & $1.194 \mathrm{e}+03$ \\
PID-PSO & $2.754962374074 \mathrm{e}+05$ & 2.096996978282 & $4.764440518909 \mathrm{e}+04$ & $1.230 \mathrm{e}+03$ \\
PID & $2 \mathrm{e} 5$ & 10 & $5 \mathrm{e} 4$ & $3.2375 \mathrm{e}+03$ \\
\hline
\end{tabular}




\section{CONCLUSION}

Meta-heuristic optimisation algorithms have been proposed in many applications to solve complex problems faster and more effectively. This study introduces a method for using a meta-heuristic optimisation algorithm, GSA, in the design of an optimum PID to open and close airplane wing tires. The meta-heuristic optimisation algorithm is applied to solve the problem in the absence of a mathematical model. GSA use also leads to improved system performance. In the study, the GSA is compared to both HAS and PSO, the PIDGSA, PID-HAS and PID-PSO, as well as the PID-ZN. Two tested were executed. The first test uses four transfer functions, while the second uses the GSA, HAS and PSO to design the optimum PID controller for the opening and closing system of the airplane wing tires. The ITAE has been formulated as a fitness function; the meta-heuristic optimisation algorithms aim to reduce ITAE during the design phase. The PID-GSA achieves better performance based on all transfer functions. Moreover, the PID-GSA achieves robust and favourable results for opening and closing the airplane wing tires of. Therefore, the PID-GSA can be effectively applied for use with the airplane wing tires.

\section{APPENDIX}

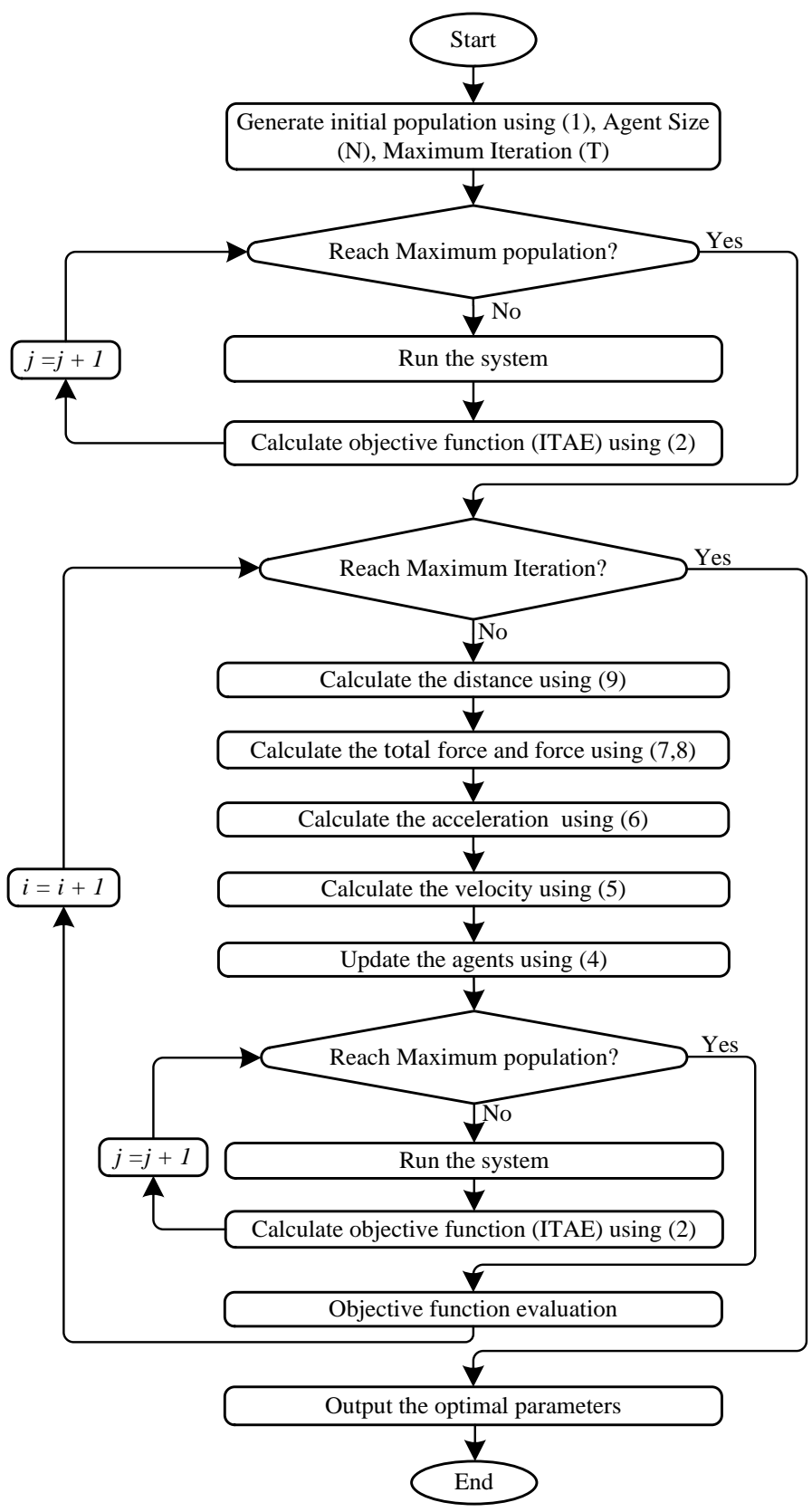

Figure 2. Implementation of the proposed GSA 


\section{REFERENCES}

[1] K. J. Astrom, and B. Wittenmark, Computer controlled system, Dover Publication Inc, Mineola New York, 2011.

[2] B. Hekimoğlu, "Optimal tuning of fractional order PID controller for DC motor speed control via chaotic atom search optimization algorithm," IEEE Access, vol. 7, pp. 38100-38114, 2019, doi: 10.1109/ACCESS.2019.2905961.

[3] Q. Chen, Y. Tan, J. Li, and I. Mareels, "Decentralized PID control design for magnetic levitation systems using extremum seeking," IEEE Access, vol. 6, pp. 3059-3067, 2018, doi:

[4] BR. Yenugula, and Zia-ur-Rahman M, "Stability control structure of hovercraft prototype utilising PID controller," Bulletin of Electrical Engineering and Informatics (BEEI), vol. 6, no. 4, pp. 348-350, 2017, doi: 10.11591/eei.v6i4.864.

[5] S. Ekinci, and B. Hekimoğlu, "Improved Kidney-inspired algorithm approach for tuning of PID controller in AVR system,” IEEE Access, vol. 7, pp. 39935-39947, 2019, doi: 10.1109/ACCESS.2019.2906980.

[6] A. Prayitno, Indrawati V, and Trusulaw II. "Fuzzy gain scheduling PID control for position of the AR. Drone," International Journal of Electrical and Computer Engineering (IJECE), vol. 8, no. 4, pp. 1939-1946, 2018, doi:

[7] K. Ogata, Modern control engineering, Prentice Hall 2010.

[8] H. Shareef, A. A. Ibrahim, and A. H. Mutlag, "Lightning search algorithm," Applied Soft Computing, vol. 36, pp. 315-333, 2015, doi: 10.1016/j.asoc.2015.07.028.

[9] H. Shareef, M. M. Islam, A. A. Ibrahim, and A. H. Mutlag, "A nature inspired heuristic optimization algorithm based on lightning," in 2015 3rd International Conference on Artificial Intelligence, Modelling and Simulation (AIMS), 2015, doi: 10.1109/AIMS.2015.12.

[10] H. Shareef, A. H. Mutlag, and A. Mohamed, "A novel approach for fuzzy logic pv inverter controller optimization using lightning search algorithm," Neurocomputing, vol. 168, pp. 435-453, 2015, doi: 10.1016/j.neucom.2015.05.083.

[11] A. Triwiyatno, S. Sumardi, and E. Apriaskar, "Robust fuzzy control design using genetic algorithm optimization approach: case study of spark ignition engine torque control," Iranian Journal of Fuzzy Systems, vol. 14, no. 3, pp. 1-13, 2017, doi: 10.22111/ijfs.2017.3238.

[12] Mutlag AH, Mahdi SQ, and Salim ON, "A new switching controller based soft computing-high accuracy implementation of artificial neural network," International Journal of Computer Science and Communication Networks, vol. 7, no. 1, pp. 1-6, 2017.

[13] J. Brest, S. Greiner, B. Boskovic, M. Mernik, and V. Zumer, "Self-adapting control parameters in differential evolution: a comparative study on numerical benchmark problems," IEEE Transactions on Evolutionary Computation, vol. 10, no. 6, pp. 646-657, 2006, doi: 10.1109/TEVC.2006.872133.

[14] L. J. Fogel, A. J. Owens, and M. J. Walsh, Artificial intelligence through simulated evolution, New York: Wiley, 1966.

[15] A. Zahir, S. Alhady, W. Othman, A. Wahab, and M. Ahmad, "Objective functions modification of GA optimized PID controller for brushed DC motor," International Journal of Electrical and Computer Engineering (IJECE), vol. 10, no. 3, pp. 2426-2433, 2020, doi: 10.11591/ijece.v10i3.pp2426-2433.

[16] H. Shareef, A. H. Mutlag, and A. Mohamed, "Random forest-based approach for maximum power point tracking of photovoltaic systems operating under actual environmental conditions," Computational Intelligence and Neuroscience, vol. 2017, pp. 1-17, 2017, doi: 10.1155/2017/1673864.

[17] Marini, Federico, and Beata Walczak, "Particle swarm optimization (PSO). A tutorial," Chemometrics and Intelligent Laboratory Systems, vol. 149, no. Part B, pp. 153-165, 2015, doi: 10.1016/j.chemolab.2015.08.020.

[18] D. Pelusi, R. Mascella, and L. Tallini, "Revised gravitational search algorithms based on evolutionary-fuzzy systems," Algorithms, vol. 10, no. 2, pp. 153-165, 2015, doi: 10.1016/j.chemolab.2015.08.020.

[19] D. Karaboga, An idea based on honey bee swarm for numerical optimization, Techn.Rep. TR06, Erciyes Univ. Press, Erciyes, 2005.

[20] A. Ghareaghaji, "A comparison between Fuzzy-PSO controller and PID-PSO controller for controlling a DC motor," Bulletin of Electrical Engineering and Informatics (BEEI), vol. 4, no. 2, pp. 130-135, 2015, doi: 10.11591/eei.v4i2.328.

[21] TM. Shin, Adam A, and Abidin AF, "A comparative study of PSO, GSA and SCA in parameters optimization of surface grinding process," Bulletin of Electrical Engineering and Informatics (BEEI), vol. 8, no. 3, pp. 11171127, 2019, doi: 10.11591/eei.v8i3.1586.

[22] Z. W. Geem, J. H. Kim, and G.V. Loganathan, "A new heuristic optimization algorithm: harmony search," Simulation, vol. 76, no. 2, pp. 60-68, 2001, doi: 10.1177/003754970107600201.

[23] E. Rashedi, H. Nezamabadi-pour, and S. Saryazdi, "GSA: a gravitational search algorithm," Information Sciences, vol. 179, no. 13, pp. 2232-2248, 2009, doi: 10.1016/j.ins.2009.03.004.

[24] X.-S. Yang, "Firefly algorithms for multimodal optimization," in Stochastic Algorithms: Foundations and Applications, SAGA 2009, Lecture Notes in Computer Sciences, vol. 5792, pp. 169-178, doi: 10.1007/978-3-64204944-6_14.

[25] X.-S. Yang, "A new met heuristic bat-inspired algorithm," in Nature Inspired Coop-erative Strategies for Optimization (NISCO 2010), Springer Berlin, vol. 284, pp. 65-74, doi: 10.1007/978-3-642-12538-6_6. 


\section{BIOGRAPHIES OF AUTHORS}

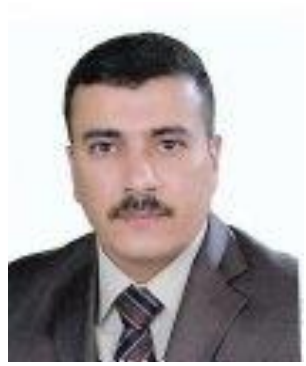

Ammar Hussein Mutlag received the B.Sc. degree in 2000 and the M.Sc. degree in 2005 in computer and control engineering from the University of Technology, Iraq, and the Ph.D. degree in control and computer engineering from University Kebangsaan Malaysia (UKM), Malaysia, in 2016. He is Assistant Professor and his research interests include intelligent controllers for renewable energy, developed optimisation algorithms, intelligent controllersbased authentication, microcontroller applications, and intelligent decision-support systems.

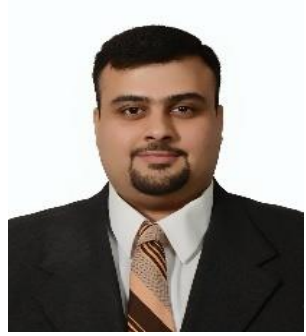

Omar Nameer Mohammed Salim received his B.Sc. Degree at 2005 and M.Sc. degree at 2008 in laser and optoelectronic engineering/college of engineering from Al_nahrin University, Baghdad-Iraq. Recently, He is an Assistant Professor from 2017 until now. The areas of interest are Optoelectronics, Electronic, fiber optics, and controlling systems.

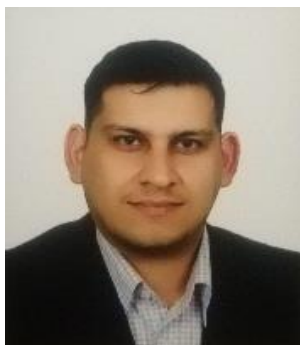

Siraj Qays Mahdi received the B.Sc. and M.Sc. Degree at 2006 and 2008 respectively in Computer Engineering Techniques/Electrical Engineering Technical College from Middle Technical University, Baghdad-Iraq. As of late, he is an Assistant Professor from 2017 until now. The areas of interest are Embedded System, WSNs and Image Processing. Recently, he is the head of Scientific Affairs in Electrical Engineering Technical College. 